\title{
Intelligent Technology Solutions at the Service of Energy Consumption Management
}

\author{
S.BOUREKKADI ${ }^{1}$, K.SLIMANI $^{1,2}$, O.El Imrani ${ }^{2}$, A.BABOUNIA ${ }^{3}$, S.KHOULJI $^{2}$, \\ A.ABOULHASSANE ${ }^{3}$ \\ ${ }^{1}$ University of Poitiers, Vienne, France. \\ ${ }^{2}$ Abdelmalek Essaâdi University, Tetuan, Morocco \\ ${ }^{3}$ Ibn Tofail University, Kenitra Morocco
}

\begin{abstract}
This project means to contribute in the decrease and justification of power utilization through its administration and control. Numerous examinations have indicated that the degree of the accessible energy stores and energy utilization is somewhat concerning. Consequently, we have built up a modest and accessible arrangement that will fill in as a technique to save this asset by following the person's utilization rate. The created application can be utilized with a basic telephone since it receives cell phone correspondence network innovation that will well impact the utilization of power, it is helpful for residents, the state, and the ages to follow by streamlining as far as utilization and thusly the month to month charges, just as its advantages on the climate.
\end{abstract}

\section{Introduction}

It is generally realized that power is a respectable asset and gives a tremendous utility to the advancement of each general public, yet whose creation, transport and appropriation require weighty speculations and involve critical upkeep cost, while its creation yields are regularly unassuming and in some cases lacking. The power is a mainstay of the modern unrest since the start of the twentieth century; it has permitted the change of our way of life, the connection among people and the Earth's current circumstance. The utilization of power has permitted the rise of numerous exercises, for example, substantial enterprises, metropolitan and mainland transport, broadcast communications, administration and media networks.

Nonetheless, the contrast between the accessible energy stores and energy utilization is exceptionally critical and concerning. Keeping up our present utilization examples will prompt a sensational lack of accessible energy in the short to medium term. Subsequently, it is currently evident that, in all areas of action, it has gotten important to change worldview and to receive new methods of creation and utilization that are suitable in the long haul. By what means would we be able to forestall power wastage and its unreliable administration?
As specialists in data framework the executives, we should contribute in the protection of a good presence and a reasonable and fair sharing of this "power" riches. One of the burdens that we needed to overcome in this work is the absence of data about the power utilization rate per family, seen that the organization liable for power dissemination rejects all sort of joint effort that incorporates sharing data. Then again, the participation of the residents was essential and valuable since they gave us all the information on their month to month utilization.

This article gives a functional arrangement, which, as it were, control and justify the power utilization through an application. The expense of our answer is sensible and needn't bother with much exertion to be received by the power dissemination organizations, contrasted with its advantages both on residents and organizations. Moreover, it will forestall the contentions between these organizations and their customers.

The objective of this part is to dissect the practical side of the framework, we utilized information that we gathered from the overview and the outcomes assisted with forming the framework from the utilitarian perspective that will give a concise arrangement to help comprehend the various segments and the primary objective of the framework. 


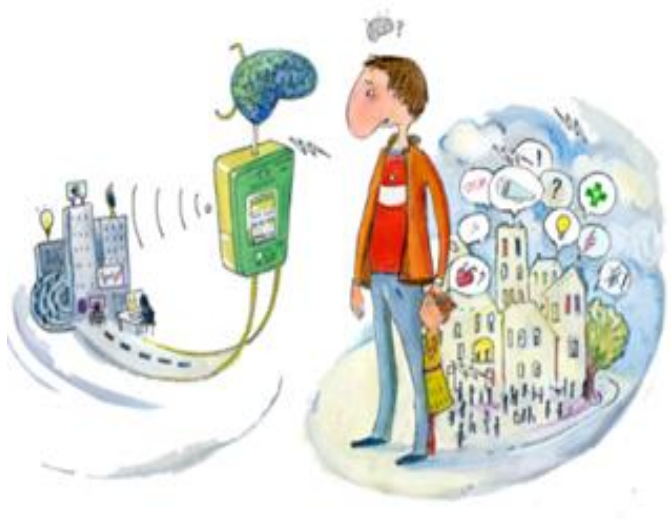

Figure 1: consumption strategy

\section{The importance of IT systems}

The human being has become so attached and obsessed with IT systems, for the fact that they took a huge place in our daily life whether in the accomplishment of our daily, personal or professional tasks. We must now involve these systems in the control of electricity consumption and the decrease of irresponsible and unacceptable behaviors in order to have better results and guaranty a decent and sufficient amount of electricity for the next generations, as well as it will ensure money saving for better uses instead of wasting it on high electricity costs.

Our anterior analyze concludes that the IT systems, when well used, can be a real and relatable asset for promoting security, stability and serving humanity.

\section{Theoretical Study Of electricity Management}

Electricity management is the activity that consists on planning, developing, distributing and managing the optimal use of electricity resources, when speaking of quality and quantity. One of the positive results is the conservation (protection) of electricity resources.

The use of electricity is traditionally distributed between three major sectors domestic, agriculture and industry

Domestic sector generally includes use at homes and municipals as well as the commercial and governmental use of electricity.

Industrial sector generally used for processing, producing, or assembling goods, including such diverse industries as manufacturing, mining, and construction.

Commercial sector the biggest single uses of electricity in the commercial sector are lighting and heating, ventilation, and air conditioning.

\section{Intelligent System for Electricity Consumption Management Functional Analysis}

To understand what people are expecting from such a project we conducted a survey with the questions presented below:

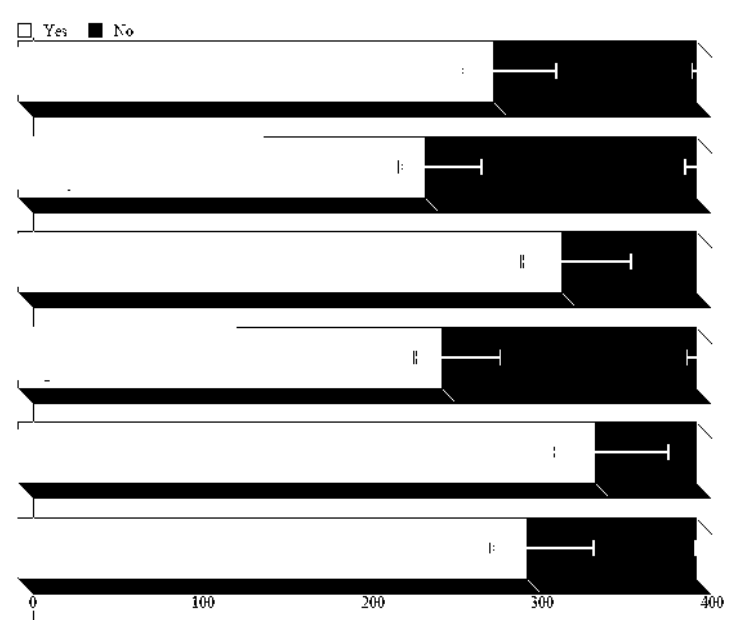

Figure 2: presentation of questionnaire result

Table 1: Questions from our survey

\section{Questions}

Do you think your electric bill is so high?

Do you think the price of the electric bill has increased over the last three years?

Do you think you are wasting electric?

Do you want to know the amount of electric consumption during the month by IT?

Do you think it is useful to receive messages informing you that you're wasting electric?

If you know how much water you consume per month, would you change the way you consume it?

\section{The Necessity of Electricity Resources Management}

- The right vision

- Specification of obligations

- Specification of duties the citizens responsibilities

- $\quad$ Alignment and consistency to establish the best public interest

- The right intervention

\section{Results}

The past investigate have affirmed that a data framework is the sensible and proficient answer for diminish the 
power use. In addition, most of our example concurred that the foundation of another, created framework adds to a superior climate of fulfillment and certainty since

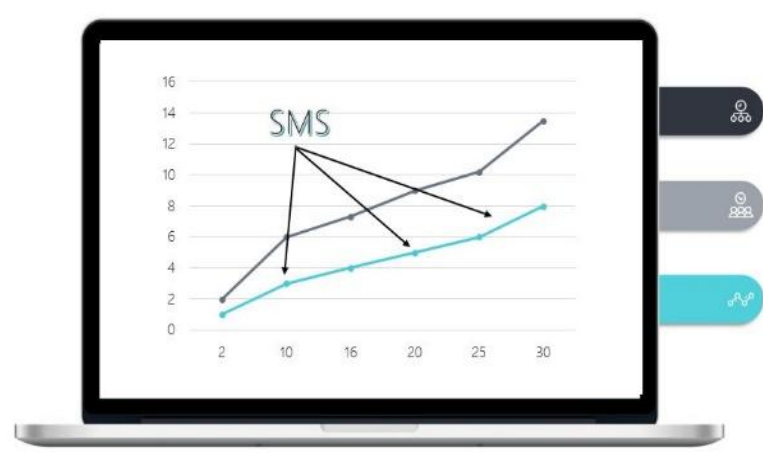

every customer will be educated regarding the subtleties of the pace of their utilization before the appearance of the receipt, which will restrict any sort of confusion and guarantee.

The figure above shows our assessment of power utilization when the use of the proposed arrangement, the bolts exhibit the minutes to share SMS smart of direction and control.

\subsection{Presentation of the system}

Intelligent system for water consumption management is composed of four elements:

A counter or sensor to measure electricity consumption

A subprogram to store customer data

A main program that transforms data to information

\subsubsection{Operating diagram}

This test bench offers a complete installation of our system. The meter (counter) measures electricity consumption and send this data to the distribution management, the latter sends the realized counting value to the supplier that contains the main program that is used to process this data and send messages to the customer

\subsubsection{Blocks diagram (synoptic diagram):}

Our system is composed of four elements that ensure the proper functioning.

At first, the meter (counter) measures the quantity of electricity consumed then sends the value to the subroutine (subprogram) that contains the client's information, then the main program does the processing and conversion of data collected, at last, a telecommunication network sends messages to the customer.

Measuring and detecting devices: Such as evolved electricity meters, physical tools on the water distribution system collects electricity flow data, pressure, quality and other determining parameters. This base layer includes acoustic and electromagnetic sensors that can help detect electricity consumption. All of these devices help calculating the physical condition of consumption in the network.

A distribution network area: Allows distributors to automatically and continuously collect data from measuring and detecting devices

Data management software (the database): Allows you to store consumer data, contains the information of each client: the full name, the telephone number, the address and the specific meter code.

Analysis and modeling software (the main program): The database provide the values of the meter to a program; the latter divides the consumption into cubic meters according to specified slices (five slices) each time the program sends a declarative message to the client.

Telecommunication channels: Contains a telecommunications network to send messages to customers about the collected data.

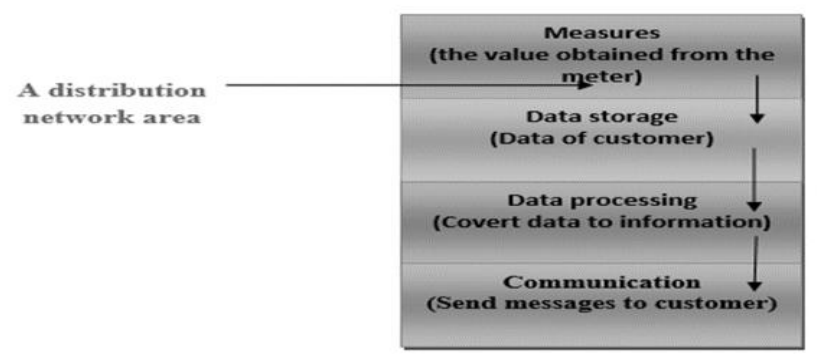

Figure 4: Blocks diagram

\subsubsection{The system's goal:}

Among the objectives of this system are:

- Correcting consumer behaviors

- Saving money to be used in other domains instead of spending it to pay expensive electricity bills.

- Minimize bill cost as much as possible.

- Contribution to the positive use of modern technology and means of communication in the purpose of humanization of computer systems. 


\section{Intelligent Electricity Management System Design}

In this part, we will present a detailed design of our system based on a black box test, in other words, we will be analyzing inputs and outputs, the possible users, services provided, at the end we will approach the bills calculation methods based on consumption entries.

\subsection{Presentation of the program}

Our project is based on a program that takes value of the quantity of electricity consumed as entry; treats the information, then sends an SMS message to the client to inform him about his level of consumption through the month.

\subsubsection{The black box test}

a. The inputs: quantity of consumed electricity.

b. The outputs: the consumer electricity.

\section{c. Program user:}

The possible users of this program are (water) and electricity distribution companies and domestic consumers.

\section{d. Services:}

Among the services provided by our program:

- Communicating with the consumer will raise the rate of satisfaction.

- The client can track and monitor his level of consumption

- The customer is not surprised when they see the consumer bill.

- Reduce and control the use of water.

\subsection{Explaining the methods of calculation of electricity consumption:}

Comparison of water consumption tariffs between two cities ( for example) : $\mathrm{C} 1$ and $\mathrm{C} 2$.

According to the Office, tariffs are specified as bellow ( model):

\begin{tabular}{lccc}
\hline City & Inferior $6 \mathrm{Kw}^{3}$ & Between $6-12 \mathrm{Kw}$ & $\begin{array}{c}\text { Between } 12 \mathrm{Kw}- \\
20 \mathrm{~m}^{3}\end{array}$ \\
\hline C1 & 0.12 & 0.32 & 0.62 \\
C2 & 0.4 & 1 & 1.3
\end{tabular}

\section{Intelligent System for electricity Consumption Management Modeling}

In this segment, we have seen the plan of our work, that is, the primary segments of canny framework for overseeing power utilization, and in the coming part we will introduce the demonstrating of our task on a PC programming language (JAVA). Before we continue to the acknowledgment of this venture, we displayed the primary program in Python.

\subsection{Algorithm Script on JAVA}

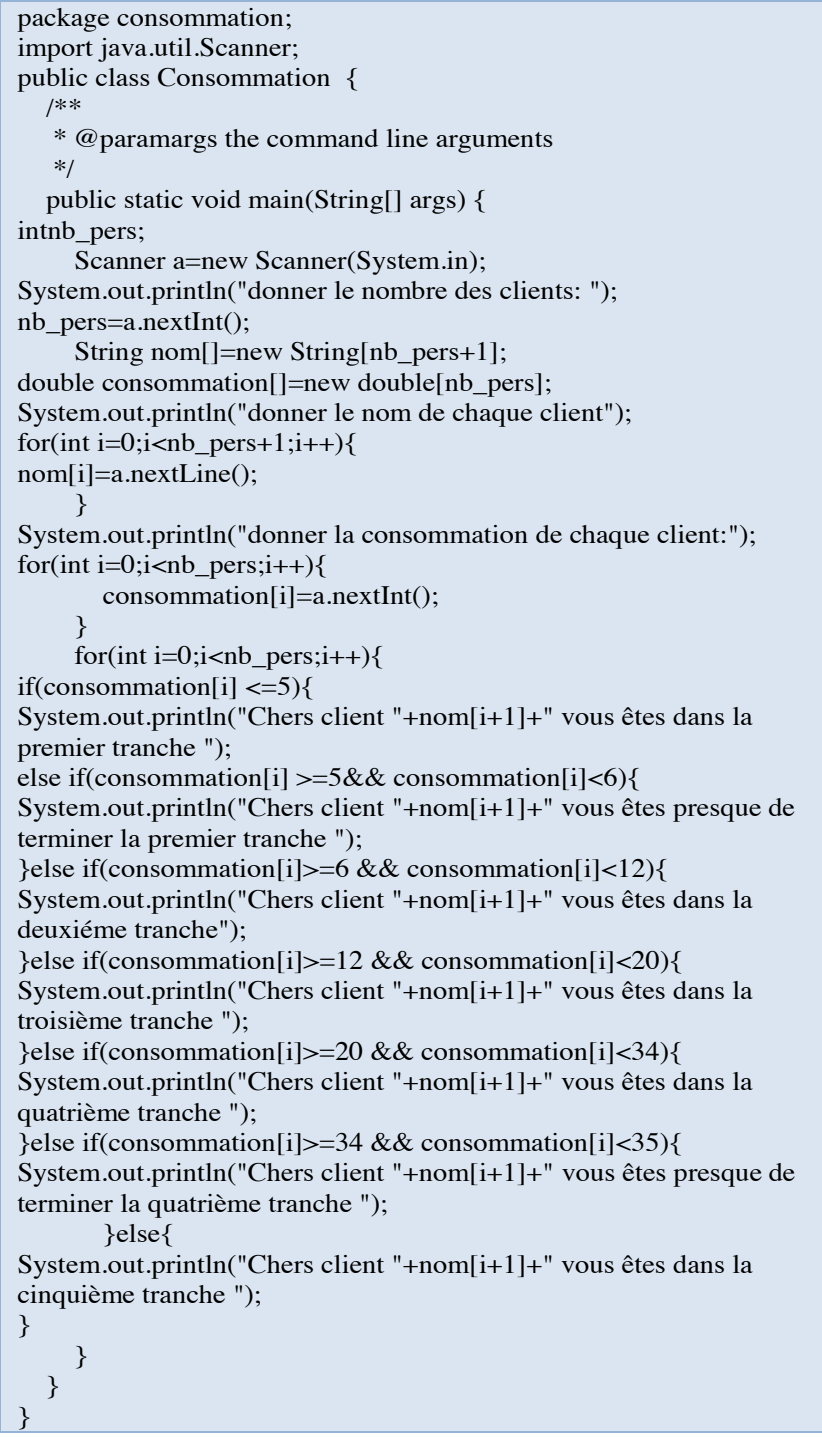

\section{Conclusion}

Electric energy is an important achievement that people have made, and it is not possible to live without electrical energy. We use it in all areas, health and recreational and in all details of life, so solutions must be devised to preserve it and use it in a correct manner. We have previously presented the same technological solution in the field of water use. These technological solutions are initiatives to create awareness among people in order to conserve the environment and energy.

\section{REFERENCES}

[1] Horrigan, L., Lawrence, R. S., \& Walker, P. (2002). How sustainable agriculture can address the environmental and human health harms of industrial agriculture. Environmental health perspectives, 110(5), 445-456. 
[2] jokic, D. and Maidment, D. R.: 1993, Application of GIS network routines for water flow and transport, J. Water Resour Plan. Manage. ASCE 119(2), 229-245.

[3] Pimentel, D., Wilson, C., McCullum, C., Huang, R., Dwen, P., Flack, J., ... \& Cliff, B. (1997). Economic and environmental benefits of biodiversity. BioScience, 47(11), 747-757.

[4] Eash, D. A.: 1994, A geographic information system procedure to quantify drainage-basin character- istics, Water Resour: Bull. AWRA 30( 1), 1-8.

[5] Johnson, L. E.: 1991, GIS visualization techniques in surface water resource planning, Proc. Nat. ASCE Conf Hydraulic Engig., Nashville, TN, 29 July-2 August, pp. 955-960.

[6] Jones, N. L. and Nelson, J.: 1992a, Drainage analysis using triangular irregular networks, Proc. 8th ConJComput. Civil Engig. GIS, pp. 719-726.

[7] Cassman, K. G., Dobermann, A., Walters, D. T., \& Yang, H. (2003). Meeting cereal demand while protecting natural resources and improving environmental quality. Annual Review of Environment and Resources, 28(1), 315-358. Robinson, K. J. and Ragan, R. M.: 1993, Geographic information system based nonpoint pollution modeling, Water Resour: Bull. AWRA 29(6), pp. 1003-1008.

[8] Ross, M. A. and Tara, P. D.: 1993, Integrated hydrological modeling with geographic information systems, J. Water Resour: Plan. Manage. ASCE 119(Z), 129-141.

[9] Ross, M. A., Schwartz, M. A., and Patrick, T. D.: 1990, Groundwater modeling with GIS: an example, Proc. Groundwater Symp., pp. 244-248.

[10] Jie, R. J. L. W. Z. (2002). Analysis on the Historical Change of Water Consumption in the Area at the Middle Reaches of the Mainstream of Heihe River [J]. Arid Zone Research, 1.

[11] BOUREKKADI, S., SLIMANI, K., IMRANI, O. E. L., et al. Toward Increasing and Investigating e-Tourism Data Warehouse through a Websites Analysis Strategy. Journal of Theoretical and Applied Information Technology, 2020, vol. 19, p. 3222-3232. 